ARTIGO

Recebido em: 10/01/2018

Aceito em: 04/04/2018

\title{
0 comportamento informacional e a competência em informação: uma abordagem para geração de inovação em micro e pequenas empresas
}

\author{
Information behavior and information literacy: an approach to \\ create innovation in micro and small businesses
}

\author{
Selma Leticia Capinzaiki OTTONICAR (selma.leticia@hotmail.com)* \\ Natália Marinho do NASCIMENTO (natalianascimento_@hotmail.com)** \\ Clemílton Luís BASSETTO (clemiltonbassetto@gmail.com)*** \\ * Doutoranda em Ciência da Informação pela Universidade Estadual Paulista Júlio de Mesquita Filho - \\ UNESP, Mestra em Ciência da Informação pela UNESP e Tecnóloga em Gestão Empresarial pela \\ Faculdade de Tecnologia - FATEC. \\ ** Doutoranda em Ciência da Informação pela Universidade Estadual Paulista Júlio de Mesquita Filho - \\ UNESP, Mestra em Ciência da Informação pela UNESP e Possui graduação em Arquivologia pela \\ Universidade Estadual Paulista Júlio de Mesquita Filho (UNESP). \\ *** Doutor em Ciência da Informação pela Universidade Estadual Paulista Júlio de Mesquita Filho - \\ UNESP, Mestre em Ciência da Informação pela UNESP, Especialização em Gestão de Pequenos \\ Negócios pela Fundação Getúlio Vargas. Especialização em Gestão Empresarial pela Fundação Getúlio \\ Vargas. Graduação em Análise de Sistemas pela Universidade do Sagrado Coração.
}

\section{RESUMO}

0 objetivo do trabalho consiste em refletir sobre a relação do comportamento informacional e da competência em informação a fim de demonstrar como tais temáticas contribuem com o processo de inovação em micro e pequenas empresas. Como metodologia utilizou-se a pesquisa bibliográfica de natureza qualitativa e do tipo exploratória. Resultou-se dessa pesquisa um quadro e um modelo conceitual que evidenciou a importância destas relações. Dessa maneira, no processo de inovação é fundamental que os profissionais possuam o comportamento informacional voltado à busca de informação e que considerem, em cada etapa, os padrões e indicadores de competência como norteadores dos processos.

Palavras-chave: Competência em Informação. Comportamento Informacional. Inovação. Micro e pequenas Empresas.

\section{ABSTRACT}

The purpose of this paper is to reflect about the relationship between information behavior and information literacy in order to demonstrate how these themes contribute to the process of innovation in micro and small businesses. As methodology, we used a bibliographic research which has a qualitative and exploratory nature. This research resulted in a conceptual framework and model that demonstrated the importance of those themes. Therefore, the information behavior is fundamental, so professionals can access information and consider the standards and indicators of information literacy as a guidance of processes.

Keywords: Information Literacy. Information Behavior. Innovation. Micro and Small Businesses.

v. 23, n. 52,2018 . p. 18-33

ISSN 1518-2924

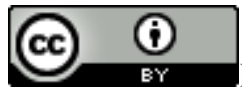

sta obra está licenciada sob uma Licença Creative Commons 


\section{INTRODUÇÃO}

Com o desenvolvimento das tecnologias de informação e comunicação (TIC) surgiram novas habilidades e capacidades, exigindo que que as pessoas aprendessem a usar a tecnologia (competência tecnológica), como buscar, acessar (comportamento informacional), analisar e aprender ao longo da vida (competência em informação) em diferentes contextos. Dessa maneira, usar os computadores e as máquinas foi o primeiro passo para atingir o objetivo de busca, entretanto, o acesso, por si só, já não garante eficácia nos processos organizacionais, sendo necessário desenvolver habilidades para lidar com a informação.

Além disso, a sociedade vive um paradoxo em relação à aprendizagem, pois existem cada vez mais indivíduos com dificuldades em aprender e isto, resulta em fracasso escolar. Concomitantemente, o período de aprendizagem aumentou por meio da educação obrigatória e com isso institui-se a aprendizagem ao longo da vida (POZO, 2007).

0 processo de inovação nas organizações influencia o seu desempenho no mercado. A criatividade gera a inovação e a aprendizagem contribui com a criatividade, ou seja, uma se sustenta sobre a outra. No processo de aprendizagem os indivíduos acessam, avaliam e usam a informação para construir conhecimento. Desse modo, não existe inovação sem considerar a aprendizagem pelas informações. Ao aprender o indivíduo transforma informações em conhecimentos que estimulam a criatividade permitindo o ato de inovar por meio das novas ideias, resultando em um ciclo "onde quanto mais se aprende mais se cria".

A competência em informação (CoInfo) e o comportamento informacional são duas variáveis fundamentais para gerar inovação nas organizações, uma vez que o processo inovativo exige das pessoas diversos saberes e autonomia para lidar com a informação transformando-a em conhecimento.

Partindo desse pressuposto, este artigo apresenta os seguintes problemas de pesquisa: Qual a relação entre a competência em informação (CoInfo) e o comportamento informacional? Como essa relação contribui com o processo de inovação? 0 objetivo consiste em refletir sobre a relação da CoInfo com o comportamento informacional a fim de demonstrar como tais temáticas contribuem com o processo de inovação em micro e pequenas empresas. As micro e pequenas empresas dependem de inovação para sobreviver no mercado altamente competitivo, nesse sentido, é fundamental que os gestores utilizem de diretrizes nesse processo, guiando cada passo dos colaboradores. Assim, a gestão empresarial pode usar a competência em informação e o comportamento informacional como temáticas estratégicas no processo de inovação, temas advindos da Ciência da Informação. A priori, pode-se dizer que a pesquisa demonstra possível interdisciplinaridade entre ambas áreas do conhecimento.

Este trabalho é considerado exploratório de natureza qualitativa e conta com uma pesquisa bibliográfica (LIMA; MIOTO, 2007) para explicar os conceitos sobre competência em informação, comportamento informacional e inovação no âmbito das micro e pequenas empresas para dar suporte à discussão e a inter-relação dos temas.

0 tema dessa pesquisa é pouco explorado e por isso é importante apresentar uma discussão inicial que sirva de aporte às pesquisas futuras. A pesquisa bibliográfica contribui para a construção dos conceitos de CoInfo e comportamento informacional para estabelecer uma relação e reflexão.

\section{REFERENCIAL TEÓRICO}

\subsection{Comportamento Informacional}

O comportamento informacional foi conceituado pela primeira vez em 1999 pelo professor Wilson. Nesse momento, se referia ao acesso, uso e compartilhamento da informação, ou seja, a clareza de que a pessoa percebe que necessita da informação 
(GASQUE; COSTA, 2010). Para Wilson (2000, p.49, tradução nossa) o comportamento informacional consiste na:

(...) totalidade do comportamento humano em relação às fontes e canais de informação, incluindo a busca de informação tanto ativa como passiva e o uso de informação. Isso inclui a comunicação pessoal e presencial, assim como a recepção passiva de informação, como a que é transmitida ao público quando este assiste aos comerciais da televisão sem qualquer intenção específica em relação à informação fornecida.

Este conceito foi considerado o mais amplo de todos, tendo em vista que engloba o usuário e às diversas possibilidades de fontes e canais de informação (busca ativa e passiva).

Esse comportamento é um processo natural dos indivíduos ao longo de sua vida. Para o seu entendimento, é necessário compreender o espaço e o tempo do acesso, uso e compartilhamento da informação (GASQUE; COSTA, 2010). Martínez-Silveira e Oddone (2007): apontam que além do contexto e da disponibilidade dos recursos tecnológicos, os processos cognitivos são fundamentais para buscar a informação necessária.

A necessidade é gerada pelo estado mental do indivíduo, por isso é uma necessidade psicológica. Desse modo o comportamento informacional possui um caráter subjetivo relacionado a motivação pessoal dos indivíduos (WILSON, 1996). Dessa maneira, antes os estudos de comportamento informacional eram mais voltados a uma perspectiva de que os indivíduos interagiam com os sistemas (apenas), atualmente o que interessa é o foco nas pessoas e o modo como elas buscam e usam a informação independentemente da fonte onde elas estão localizadas. Isso aconteceu no momento em que os métodos etnográficos foram inseridos nestes estudos, pois antes eram utilizados apenas os métodos quantitativos.

Com o intuito de auxiliar a teoria a explicar os fenômenos que abarcam a temática vários modelos foram criados, pois como explicita Wilson (1999, p.250):

\footnotetext{
Um modelo pode ser descrito como um quadro para pensar sobre um problema e pode evoluir para uma declaração sobre as relações entre proposições teóricas. A maioria dos modelos em geral no campo de comportamento informacional são afirmações, muitas vezes na forma de diagramas, que tentam descrever uma atividade de busca informacional, as causas e consequências dessa atividade, ou as relações entre as fases do comportamento de busca informacional.
}

De uma maneira resumida, alguns desses modelos são: Wilson (1981) composto de doze estágios e atua no nível da necessidade, mas especificamente a busca informacional; Krikelas (1983) composto de treze estágios e atua no nível da necessidade de criar um ambiente; Leckie, Pettigrew e Sylvain (1996) composto de seis estágios e está voltado para as atividades de trabalho; Brystrom e Jarvelin (1995) composto de nove estágios e abrange tarefas subjetivas; Savolainen $(1995,2005)$ composto de mais de quinze estágios e aborda a vida diária; Johnson (1997) composto de sete estágios e aborda as questões demográficas, as experiências diretas, relevância e crenças; e por fim, o segundo modelo de Wilson (1996, 1999) composto por vinte estágios e aborda as questões de contexto e pessoa/indivíduo no contexto (CASE, 2007, p.123-139, tradução nossa).

Neste artigo utilizamos o modelo de Wilson (1981), conforme a figura 1. 


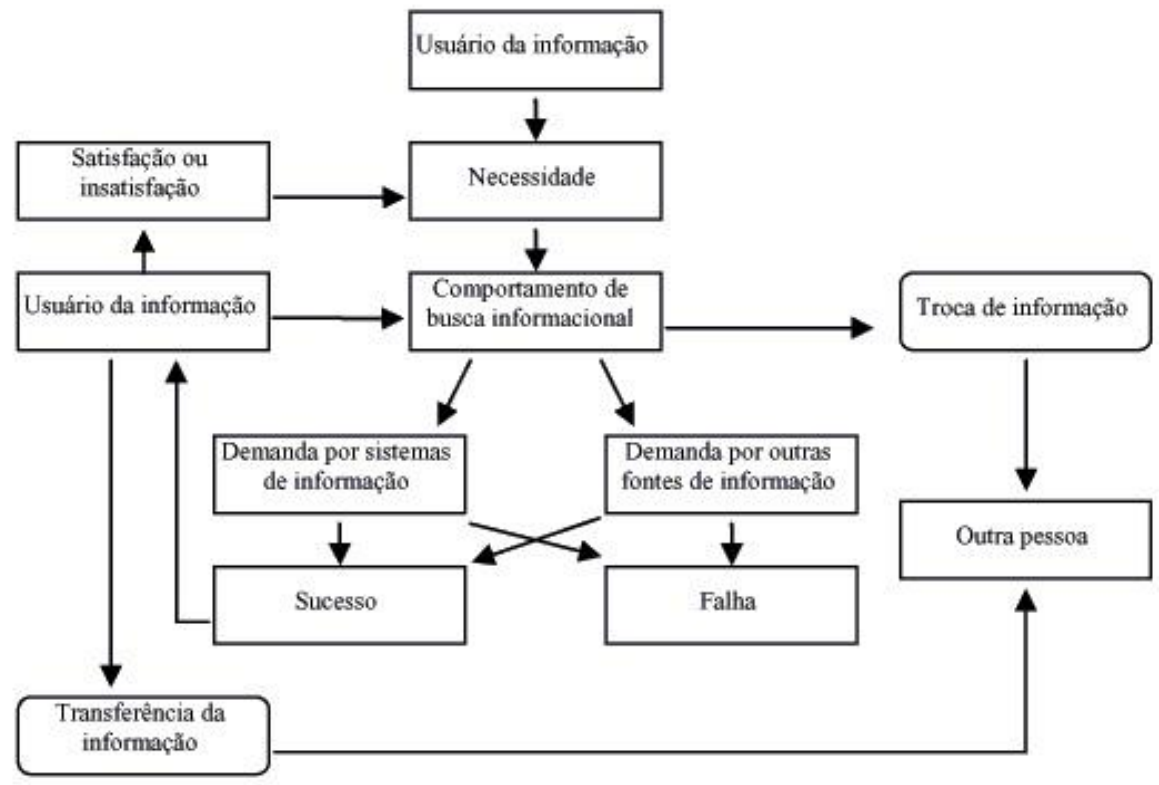

Figura 1: Modelo de comportamento informacional de Wilson.

Fonte: Wilson (1981).

Ressalta-se que os referidos padrões foram escolhidos porque demonstram de maneira detalhada os indicadores de desempenho e os resultados desejáveis de cada padrão (Apêndice A), a escolha do Modelo de Comportamento Informacional de Wilson ocorreu devido ao fato de que é um clássico na literatura e representa as principais etapas do comportamento de busca.

A competência em informação está relacionada com o comportamento informacional, à medida que considera as atitudes das pessoas como parte de seu conceito. Além da questão comportamental, essa competência considera as capacidades e experiências dos indivíduos como elementos impactantes em sua concepção. Sendo assim, a competência em informação complementa os estudos de comportamento informacional.

\subsection{Competência em Informação}

A competência em informação (Coinfo) foi citada pela primeira vez por Paul Zurkowski no de 1974 e a partir de então, estudos e pesquisas vem sendo desenvolvidos para incorporar a CoInfo na vida prática das pessoas em diversos âmbitos: escolar, gerencial e social.

Assim como a aprendizagem, a competência em informação torna-se presente em diversas organizações e contextos. De acordo com Coutinho e Lisboa (2011) a educação no século XXI possui inúmeros desafios, o principal deles é:

[...] desenvolver nos estudantes competências para participar e interagir num mundo global, altamente competitivo que valoriza o ser-se flexível, criativo, capaz de encontrar soluções inovadoras para os problemas de amanhã, ou seja, a capacidade de compreendermos que a aprendizagem não é um processo estático mas algo que deve acontecer ao longo de toda a vida (COUTINHO; LISBÔA, 2011, p. 5).

Dessa maneira, a escola contribui e influencia na sociedade quando forma cidadãos para atuar em um mundo que demanda a sustentabilidade, portanto a CoInfo não está voltada apenas para a capacitação de profissionais para atuar em determinada área do 
conhecimento, mas para que as pessoas sejam atores em toda a sua vida, deixando de receber as informações de forma passiva.

0 aprendizado ao longo da vida representa um novo cenário de valorização tanto do aprendizado formal quanto informal, pois segundo Aníbal (2013, p. 25):

[...] o reconhecimento destas aprendizagens não escolares é, paradoxalmente, uma medida humanista e de caráter emancipatório, pelo que essa validação altera, em termos de reconhecimento social de espaços, contextos e tempos de aprendizagem que, até então, eram considerados menores, ou insignificantes, quando comparados com a instituição escolar, detentora exclusiva da produção do saber.

No novo contexto em que o ser humano está inserido é possível aprender por meio da mídia e das TIC, Campello (2003, p.33) apresenta que a "fluência em tecnologia é apenas um dos componentes da competência informacional", um exemplo, de aprendizagem são os cursos online, visto que podem ser acessados por pessoas em diferentes cidades, estados e até mesmo países. Ademais, as notícias são fornecidas em tempo real e isso possibilitou uma agilidade e aceleração do processo de conhecimento.

Contudo, a sociedade da informação consiste em um ambiente "tão diferente e mutante que exige novas habilidades para nele se sobreviver" (CAMPELLO, 2003, p.33), por isso, é importante saber como buscar, acessar e avaliar as informações para que sejam usadas de modo a solucionar um objetivo, levando em consideração as questões éticas e legais com responsabilidade. É preciso desenvolver a capacidade de filtrar a informação de forma inteligente e eficaz.

Complementando, Belluzzo (2003, p. 50) explica que:

Competência em Informação constitui-se em processo contínuo de interação e internalização de fundamentos conceituais, atitudinais e de habilidades específicas como referenciais à compreensão da informação e sua abrangência, em busca da fluência e das capacidades necessárias à geração do conhecimento novo e sua aplicabilidade ao cotidiano das pessoas e das comunidades ao longo da vida.

Para a Unesco (2013, p.29), a CoInfo é definida como "um conjunto de competências que permite aos cidadãos acessar, recuperar, avaliar e usar, bem como criar e compartilhar informações e conteúdo de mídia em todos os formatos, usando várias ferramentas de forma crítica, ética e eficaz", além disso, menciona que tudo isso para participar e se envolver em atividades pessoais, profissionais e sociais.

Para Bruce (1999, p.34, tradução nossa), a CoInfo é vista como "uma parte do caráter das organizações de aprendizagem, bem como uma característica importante dos funcionários da organização".

A competência em informação tomou uma dimensão inimaginável e vem sendo objeto de diferentes pesquisas aplicadas em diversos contextos, demonstrando sua flexibilidade e contribuição para o desenvolvimento sustentável e cidadania. Para Rasteli e Cavalcante (2013, p.168) "os componentes que sustentam o conceito de competência em informação são: o processo investigativo; o aprendizado ativo; o aprendizado independente; o pensamento crítico; o aprender a aprender e o aprendizado ao longo da vida".

Em 1989 foi publicado pelo Comitê Presidencial da American Library Association (ALA) um relatório que reconhecia a importância da área de competência em informação, neste documento também era abordado os critérios que definem uma pessoa como competente em informação, segundo este documento essas pessoas devem ser capazes de: 
[...] reconhecer quando a informação é necessária e [têm] a habilidade de localizar, avaliar e usar efetivamente esta informação [Essas pessoas] aprenderam como aprender. Elas sabem como aprender porque sabem como a informação é organizada, como encontrá-la e como usar a informação de forma que os outros também possam aprender com ela. (AMERICAN LIBRARY ASSOCIATION, 1989, tradução nossa).

Para ser considerado competente em informação, o indivíduo precisa adquirir um comportamento de busca, avaliação e uso da informação a fim de compartilhar o conhecimento, processo conhecido como comportamento informacional. A competência em informação também contribui com o ambiente das empresas, à medida que estimula a avaliação das informações e suas fontes. Os trabalhadores necessitam de informação para tomar decisão, solucionar um problema e realizar uma atividade específica, portanto esta competência é elemento norteador dos processos empresariais, principalmente da inovação.

\subsection{Inovação em Micro e Pequenas Empresas (MPE)}

Antes, de discorrer sobre o tema em epígrafe, é importante conceituar o que são MPE. De acordo com a Lei 123/2006, considera-se como microempresa a pessoa jurídica que, aufira, em cada ano-calendário, receita bruta igual ou inferior a $\mathrm{R} \$ 360.000,00$ e como pequena empresa a pessoa jurídica que aufira, em cada ano-calendário, receita bruta superior a $R \$ 360.000,00$ e igual ou inferior a $R \$ 3.600 .000,00$. Sendo que, a partir de $01 / 01 / 2018$, esse limite passa a ser de $\mathrm{R} \$ 4.800 .000,00$, de acordo com a Lei Complementar $155 / 2016$.

Por outro lado, uma característica marcante do universo das MPE, segundo Schell (1995) é que possuem um pequeno número de funcionários e também:

a) Uma estrutura organizacional simplificada, com pouco ou nenhum nível hierárquico e alta concentração de autoridade;

b) Ocupa espaço bem definido no mercado em que atua;

c) Possui maior intensidade de trabalho;

d) A gestão geralmente não distingue assuntos particulares e profissionais, misturando, em muitos casos, a conta bancaria pessoal com a da sua empresa.

Ainda, segundo Schell (1995), a grande vantagem da MPE é que, por produzir em pequenas séries, tem maior possibilidade de responder às oportunidades em menor tempo atendendo mercados específicos e especializados.

Rodrigues (apud MOREIRA; SOUZA, 2004) destaca outras características que podem ser sintetizadas da seguinte maneira:

a) A empresa, em geral, é de propriedade de um indivíduo ou de um pequeno grupo de pessoas;

b) É administrada pelo(s) proprietário(s) de forma autônoma e, mesmo quando profissionalizada, caracterizam-se como centro de decisões;

c) 0 capital é financiado, em sua grande maioria, pelo proprietário;

d) Possui área de operação limitada à sua localização ou, no máximo, vinculada à sua região geográfica;

e) Sua atividade produtiva não ocupa posição de destaque ou predominância em relação ao mercado.

Gonçalves e Koprowski (1995) também ressaltam características das pequenas empresas: usam trabalho próprio ou de funcionários; não possuem administração especializada fora da empresa; não pertencem a grupos financeiros e econômicos e não possuem produção em escala; têm organização rudimentar; são receptoras de mão de obra 
liberada do setor rural; possuem estreita relação pessoal do proprietário com os empregados, clientes e fornecedores; têm dificuldade em obter créditos; falta-lhes poder de barganha nas negociações de compra e venda e apresentam integração bastante estrita com a comunidade local; sua direção é pouco especializada; têm falta de acesso ao capital por meio do capital organizado; têm dependência de mercados e de fontes de suprimentos próximos; e mostram baixa relação de investimento/mão de obra empregada.

De acordo com pesquisas realizadas pelo Serviço de Apoio às Micro e Pequenas Empresas (SEBRAE, 2017), as micro e pequenas empresas (MPE) representam um universo de $98 \%$ das organizações existentes no estado de São Paulo, as quais empregam 49\% da força trabalhadora e são responsáveis por $37 \%$ da folha de salários.

Ainda, segundo o SEBRAE (2017), em comparação com outros países, o Brasil possui uma MPE para cada 21 habitantes, sendo o detentor da maior marca de habitantes por MPE no mundo. Ficando à frente de países como Alemanha, Reino Unido, França, Japão, Dinamarca e Áustria.

Pelos resultados apresentados na pesquisa do SEBRAE (2017), pode-se perceber o alto nível de importância desses empreendimentos na economia do País e seu impacto na sociedade brasileira, daí o objeto do estudo ora proposto estar focado nesse tipo de organização.

No entanto, vale lembrar que a pesquisa do SEBRAE (2017) aferiu situação preocupante envolvendo a taxa de mortalidade (fechamento) das MPE com 23,7\% até segundo ano de atividade, ou seja, 1 em cada 5 empresas fecham antes de completarem 2 anos de mercado. Essa taxa de mortalidade chega a $58 \%$ no 5 o ano no mercado.

Diante desse cenário, para se destacar, as empresas devem desenvolver vantagens competitivas, que segundo Vanconcelos e Cyrino (2000), ocorre quando uma empresa apresenta níveis de desempenho econômico superiores à média de seu setor.

Porter (1989) afirma que a vantagem competitiva ocorre quando uma empresa consegue criar uma competência ou valor superior, que a distingue das demais, para seus compradores. Desse modo, para o autor, essa empresa conseguirá vantagem competitiva sobre os concorrentes caso opte por um dos dois tipos básicos de estratégia: menor custo ou diferenciação.

Nas discussões que permeiam a competitividade empresarial, a inovação tem ocupado um lugar central, porque é base para a formulação de políticas de desenvolvimento regional. Em estudos realizados em países desenvolvidos, estima-se que a inovação é responsável por até $90 \%$ do crescimento da produtividade (QUANDT, 2005).

Entende-se por inovação "a introdução de novidade ou aperfeiçoamento no ambiente produtivo ou social que resulte em novos produtos, processos ou serviços" (LEI 10.973/2004).

A Lei 11.196/2005, chamada Lei do Bem, classifica inovação com a:

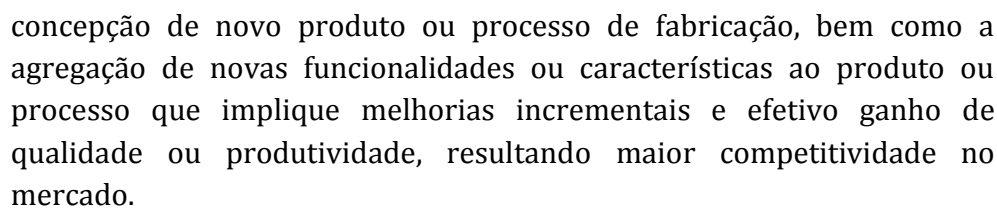
agregação de novas funcionalidades ou características ao produto ou processo que implique melhorias incrementais e efetivo ganho de qualidade ou produtividade, resultando maior competitividade no mercado.

Para o SEBRAE/PR (2015), nas organizações empresariais, a inovação tem três propósitos: criar diferencial, neutralizar a concorrência e aumentar a produtividade. Um produto, processo ou método de gestão pode ser considerado inovador se é novo para a empresa, ainda que seja lugar comum no setor de negócio, na concorrência ou em outros negócios. 
Segundo o Manual de Oslo (2004), estes são os tipos de inovação:

- Inovação de produto: bem ou serviço novo ou significativamente melhorado;

- Inovação de processo: método de produção ou distribuição novo ou significativamente melhorado;

- Inovação de marketing: novo método de marketing com mudanças significativas na concepção do produto ou da embalagem, no posicionamento do produto, na promoção ou na fixação de preços;

- Inovação organizacional: novo método organizacional nas práticas de negócio da empresa, na organização de seu local de trabalho ou em suas relações externas.

Desse modo, reforçando e ampliando os conceitos apresentados, de acordo com Quandt (2005) a inovação é essencial para ampliar as oportunidades de ganhos econômicos e sociais das cidades, regiões e países.

Em complemento aos conceitos apresentados por renomados autores que classificam e conceituam inovação, existem entidades de fomento que além de se apoiarem em tais definições, aplicam modelos de análise e validação de projetos de inovação que identificam e determinar o nível de inovação e seus impactos nos negócios e na sociedade ao disponibilizar editais para apoio e incentivo à pesquisa da inovação.

Nesse sentido, a Financiadora de Estudos e Projetos (FINEP, 2016), entende ser importante identificar os seis elementos sintetizados a seguir, em suas análises de projetos de inovação:

1. Risco - considera o estágio do desenvolvimento e a distância em relação a comercialização; a complexidade da tecnologia empregada; a estrutura gerencial para o desenvolvimento do projeto; e a diferença entre cultura de empresa inovadora considerando o projeto de inovação;

2. Abrangência e intensidade - considera o alcance da inovação. Verifica se a inovação considerada só para a empresa, para uma região, país ou para o mundo e se a inovação tem característica incremental ou radical;

3. Conhecimento envolvido - verifica se o conhecimento empregado na inovação é técnico ou de mercado; identifica quantas e quais pessoas detêm esse conhecimento e quais capacidades podem ser diferenciadas; considera se o conhecimento apropriado é suficiente para gerar uma barreira de entrada; e se a inovação merece ser protegida;

4. Barreiras - verifica a existência de barreiras de entrada para outras organizações realizarem a mesma inovação. Além de identificar as características que configuram essa barreira. Tais como: uso de patente; conhecimento não dominado pela concorrência; tempo necessário para a concorrência atingir o mesmo patamar; e pela necessidade de alto volume de recursos financeiros para atingir o mesmo patamar;

5. Impactos e aderência ao negócio - verifica a aderência da inovação à estratégia de negócio; identifica se a inovação resultará no crescimento da empresa; avalia se a inovação causará o aumento da produtividade na mesma; se o crescimento (baseado na inovação) se dará por aumento no faturamento ou pelo aumento no rendimento, ou seja, ganho de margem de lucro ou maior lucro agregando valor ao produto;

6. Externalidades - verifica quais os principais benefícios sociais, econômicos e ambientais decorrentes do projeto. Avaliando o desenvolvimento regional, fortalecimento da cadeia produtiva, exportação, parcerias com Universidades e Institutos de Ciência e Tecnologia (ICTs), geração de emprego e sustentabilidade. 
As definições e classificações apresentadas ilustram a abrangência e complexidade do tema, além de fortalecer e evidenciar a dificuldade de incorporação dos mesmos, pelos empresários. Ao confrontar a teoria com a prática, considerando a realidade brasileira, para o Global Competitiveness Report (2016) ou Relatório Global de Competitividade, organizado pelo Fórum Econômico Mundial, o Brasil ocupava a $48^{\mathrm{a}}$ posição em 2012, caiu para a $76^{\mathrm{a}}$ colocação em 2015, chegando, em 2016, a ocupar o $81^{\circ}$ lugar (Tabela 1). Ou seja, no intervalo de quatro anos (2012-2016) o país perdeu 33 posições, ficando atrás, por exemplo, dos demais países que, ao lado do Brasil, formam os BRICS (Rússia, Índia, China e África do Sul).

Tabela 1 - Ranking global de competitividade de países selecionados.

\begin{tabular}{l|l}
\multicolumn{1}{c|}{ Primeiros colocados } & \multicolumn{1}{c}{ BRICs } \\
\hline $1^{\circ}$ Suíça & $28^{\circ}$ China \\
\hline $2^{\circ}$ Singapura & $39^{\circ}$ Índia \\
\hline $3^{\circ}$ Estados Unidos & $43^{\circ}$ Rússia \\
\hline $4^{\circ}$ Países Baixos & $47^{\circ}$ África do Sul \\
\hline $5^{\circ}$ Alemanha & $81^{\circ}$ Brasil \\
\hline
\end{tabular}

Fonte: Global Competitiveness Report (2016).

Experiências de outros países evidenciam que investimentos em inovação, além de constituir fator de competitividade, têm relação direta com o aumento da produtividade e motor do crescimento econômico dos países. Nesse sentido, para enfrentar a crescente competição global por mercados, as nações têm dado grande relevância aos fatores relacionados ao desenvolvimento científico, tecnológico e à inovação, tanto que, mesmo em período de crise, muitos países continuaram ampliando o volume de recursos direcionado a atividades de pesquisa e desenvolvimento (OCDE, 2016).

As informações apresentadas reforçam a necessidade do desenvolvimento de competências e habilidades específicas para que o Brasil consiga atingir melhores níveis de desempenho com relação à inovação, ciência e tecnologia e, em decorrência, diminuir as taxas de mortalidade das MPE, que têm forte reflexo na geração de emprego e renda.

\section{PROCEDIMENTOS METODOLÓGICOS}

0 arcabouço teórico desse trabalho foi construído com base em uma pesquisa bibliográfica sobre os temas: competência em informação, comportamento informacional e inovação. Para tanto, pesquisou-se artigos científicos da área da Ciência da Informação e da Administração de Empresas (Gestão). Além disso, buscou-se as temáticas nas bases de dados Index Psi Periódicos (INDEX), Library and Information Science (LISA), Biblioteca Digital Brasileira de Teses e Dissertações (BDTD -IBICT) e em periódicos brasileiros e internacionais.

Também realizou-se a busca nas revistas brasileiras: RICI (Unb), RDBCI (UNICAMP), Encontros Bibli (UFSC), Transinformação (PUC-Campinas) e Perspectivas em CI (UFMG) que são de qualidade na área da Ciência da Informação. Conta também com artigos da: Revista de Educação, Revista Katál, Revista de Administração de Empresas. No que tange as revistas internacionais, as escolhidas foram: Informing Science Research, Journal of Documentation, Information Research etc. 
Para este trabalho, escolheu-se como parâmetros a CoInfo e os padrões e indicadores estruturados e traduzidos por Belluzzo (2007) por se adequar ao contexto brasileiro e trazer os resultados almejados que poderão ser detalhados em pesquisas futuras.

Como resultado, apresenta-se um quadro teórico, com a discussão sobre a conexão dos três temas propostos e um modelo de processo de inovação baseado no comportamento informacional e na competência em informação.

\section{RESULTADOS E DISCUSSÃO}

Quando apresentamos as temáticas observamos uma grande relação entre elas, tendo em vista que para propor as competências em informação é preciso conhecer o comportamento informacional dos indivíduos, pois este, necessita estar apto a trabalhar com inovação em MPE, para contribuir com avanços qualitativos para este setor.

Percebe-se que ao analisar o comportamento informacional, a competência em informação e o processo de inovação, partindo das perspectivas de Wilson, Belluzzo e dos critérios de inovação proposto pelo FINEP, que os três elementos estão inter-relacionados no que tange cada etapa (ver Quadro 3).

Quadro 3 - Inter-relação entre comportamento informacional, competência em informação e o processo de inovação.

\begin{tabular}{|c|c|c|}
\hline $\begin{array}{l}\text { Etapas do Modelo de } \\
\text { Comportamento } \\
\text { Informacional } \\
\text { (WILSON, 1981) }\end{array}$ & 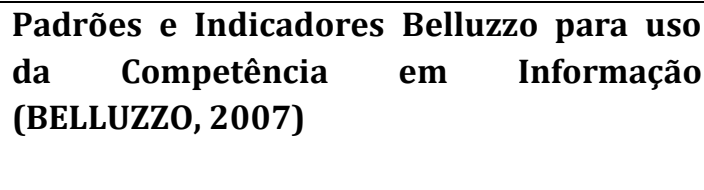 & $\begin{array}{l}\text { Processo de Inovação na } \\
\text { MPE - Critérios de } \\
\text { inovação FINEP (2016) }\end{array}$ \\
\hline Necessidade & $\begin{array}{l}\text { Padrão } \mathbf{1}-\text { A pessoa competente em } \\
\text { informação determina a natureza e a extensão } \\
\text { da necessidade de informação. }\end{array}$ & $\begin{array}{l}\text { Risco } \\
\text { Abrangência e intensidade }\end{array}$ \\
\hline $\begin{array}{l}\text { Demanda por Sistemas de } \\
\text { Informação }\end{array}$ & $\begin{array}{l}\text { Padrão } 2-\text { A pessoa competente em } \\
\text { informação acessa a informação necessária } \\
\text { com efetividade. }\end{array}$ & Conhecimento envolvido \\
\hline $\begin{array}{l}\text { Demanda por outras } \\
\text { Fontes de Informação }\end{array}$ & $\begin{array}{l}\text { Padrão } 3-A \text { pessoa competente em } \\
\text { informação avalia criticamente a informação e } \\
\text { as suas fontes. }\end{array}$ & $\begin{array}{l}\text { Conhecimento envolvido } \\
\text { Barreiras }\end{array}$ \\
\hline $\begin{array}{l}\text { Troca/Transferência de } \\
\text { Informação }\end{array}$ & $\begin{array}{l}\text { Padrão } 4-\text { A pessoa competente em } \\
\text { informação, individualmente ou como } \\
\text { membro de um grupo, usa a informação com } \\
\text { efetividade para alcançar um objetivo/obter } \\
\text { um resultado. }\end{array}$ & $\begin{array}{l}\text { Conhecimento envolvido } \\
\text { Barreiras } \\
\text { Impactos e aderência ao } \\
\text { negócio }\end{array}$ \\
\hline Satisfação ou Insatisfação & $\begin{array}{l}\text { Padrão } \mathbf{5}-\text { A pessoa competente em } \\
\text { informação compreende as questões } \\
\text { econômicas, legais e sociais da ambiência do } \\
\text { uso da informação e acessa e usa a informação } \\
\text { ética e legalmente. }\end{array}$ & Externalidades \\
\hline
\end{tabular}

Fonte: elaborado pelos autores.

A necessidade ocorre quando o indivíduo percebe que precisa de determinada informação e nessa etapa há uma angústia para realizar este processo. Além disso, é importante verificar a extensão dessa necessidade, ou seja, se é uma informação simples ou complexa. No processo de inovação, o risco é um dos elementos propulsores da necessidade de informação. A incerteza a respeito do sucesso e das falhas de um produto ou novo serviço contribui para que os gestores busquem informação sobre um novo projeto. A necessidade de informação faz com que os profissionais acessem informações sobre o estágio do 
desenvolvimento e a distância em relação à comercialização; a complexidade da tecnologia empregada; a estrutura gerencial para o desenvolvimento do projeto; e a diferença entre a cultura de empresa inovadora considerando o projeto de inovação. A necessidade é provocada por um fator contextual, mas que advém segundo Wilson (1996) de aspectos cognitivos do indivíduo.

Não obstante, a abrangência e intensidade (são variáveis possíveis). Para Rank, Emediato e Osorio (2008, p.14) "enquanto quesito intensidade a inovação pode ser incremental, radical e revolucionária; no quesito abrangência ela pode ser para a empresa, para o mercado ou para o mundo", ou seja, este é também outro fator que impacta na necessidade de informação, tendo em vista que identifica a amplitude da inovação, se é útil apenas para a empresa ou se poderão influenciar outros países. Essa necessidade faz com que os gestores e demais profissionais da organização busquem informação a respeito dos impactos da inovação do produto ou serviço para o ambiente, sociedade e meio ambiente.

Uma vez vista a necessidade de informação, a pessoa se engaja no acesso a informação e demanda sistemas de informação. Nesse momento é importante saber como utilizar as tecnologias de informação e comunicação e definir uma estratégia de busca. 0 acesso à informação precisa do conhecimento envolvido do processo de inovação, pois por meio da busca os gestores e profissionais analisam se o conhecimento empregado na inovação é técnico ou de mercado. Além disso, identificam a quantidade e o nome dos indivíduos que detêm esse conhecimento e como alocar suas competências no desenvolvimento do projeto inovador. Após buscar as informações, a pessoa verifica se estas são completas e suficientes para solucionar o problema, caso contrário realiza um novo acesso e se atenta às fontes de informação e sua confiabilidade. Esta etapa é muito importante, pois uma desinformação ou informação incorreta poderá determinar o sucesso ou fracasso do processo de busca informacional.

Ao usar a informação e tomar a decisão, as informações acabam sendo disseminadas em um grupo de indivíduos que estão envolvidos com o acesso para alcançar um objetivo específico com efetividade. Nesta fase pode ocorrer uma análise do processo pelo sujeito a partir do sucesso ou fracasso. Em relação ao conhecimento envolvido, o gestor e os profissionais consideram se o conhecimento apropriado é suficiente para gerar uma barreira de entrada.

Essa barreira de entrada se refere a barreira que a empresa faz para impedir que os concorrentes se apropriem do produto ou serviço inovador, portanto, os profissionais estudam se a inovação pode ser protegida. Assim, existem barreiras a essa inovação, por isso os indivíduos observam a existência de barreiras de entrada para outras organizações realizarem a mesma inovação. Além de identificar as características que configuram essa barreira. Essas barreiras podem ser o uso de patente, conhecimento não desenvolvido pela concorrência, tempo necessário para a concorrência atingir o mesmo patamar e a necessidade de alto volume de recursos financeiros.

Com isso, os gestores e profissionais compreendem as consequências do alcance da meta desejada. Tais consequências podem ser econômicas, políticas e legais respeitando os direitos de propriedade intelectual e usando a informação com responsabilidade. No processo de inovação os impactos e aderência ao negócio refletem essas etapas da competência em informação e do comportamento informacional.

Os gestores e profissionais empresariam analisam a conformidade da inovação com a estratégia de negócios e investigam se a inovação irá contribuir com o crescimento da empresa. Além disso, avaliam se a inovação causará o aumento da produtividade, se a competitividade se dará por aumento na margem de lucro por meio da agregação de valor do produto ou serviço. É no final do processo que o indivíduo percebe se ficou satisfeito, a insatisfação estimula o reinício do ciclo e o diagnóstico das falhas, contribuindo para que o indivíduo realize o feedback. 
Portanto o comportamento informacional e a competência em informação são assuntos que se complementam e não podem existir sem o outro, pois a CoInfo envolve, dentre outros fatores, as atitudes e ações que se concretizam por meio do comportamento de busca, acesso e uso da informação. Do mesmo modo que o comportamento informacional necessita de habilidades e capacidades desenvolvidas a priori cognitivamente e, também, da experiência pessoal.

Os padrões e indicadores utilizados para diagnóstico da CoInfo também servem como aporte às pesquisas sobre comportamento Informacional, para isso é necessário utilizar aqueles relacionados com as habilidades e atitudes do indivíduo. Nesse sentido é perfeitamente cabível utilizar os padrões e indicadores de competência em informação para medir as etapas de determinado modelo de comportamento informacional.

Defende-se então que não existe uma superioridade entre a CoInfo e o comportamento informacional, ambos se complementam e há uma linha tênue em sua diferenciação. Para tanto faz-se necessário utilizar de estratégias como desenvolver quadros, figuras, mapas conceituais de modo que ambos se complementem.

A diferenciação consiste em que a competência em informação é o aprendizado ao longo da vida com a finalidade de melhorar a vida profissional, cotidiana, social, religiosa, etc. Já o comportamento informacional são as ações e comportamentos adotados pelo indivíduo para obter esse aprendizado e alcançar um objetivo.

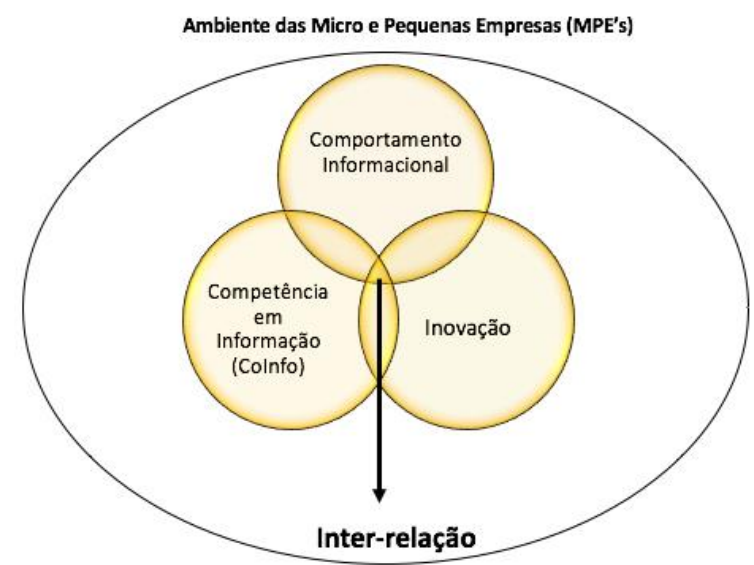

Figura 2: Modelo da inter-relação entre o comportamento informacional, competência em informação e inovação.

Fonte: elaborado pelos autores.

A competência em informação engloba as habilidades, capacidades e experiências dos indivíduos ao longo de sua vida (BELLUZZO, 2007; BELLUZZO, FERES, 2015; BRUCE, 1999; ACRL, 2014). Participa dos diferentes contextos que abarcam o social, ou seja, a atuação profissional e seu desenvolvimento na sociedade (OTTONICAR; VALENTIM; FERES, 2015; LLOYD, 2007; YAFUSHI, 2016) e o lazer (BRUCE, 2016). Diante disso, para ser competente em usar a informação de maneira inteligente é necessário, primeiramente, adquirir um comportamento de acesso a informação, isto significa um perfil ativo para buscar conhecer e aprender aquilo que não se sabe, "sair da zona de conforto", pois muitas vezes os indivíduos consideram-se satisfeitos em saber/conhecer o mínimo possível. Esse comportamento faz parte da vida dos indivíduos por meio da comunicação (WILSON, 1999).

No que tange o desenvolvimento das organizações, existe um elemento essencial que depende dos indivíduos, este elemento é a inovação. Para que a inovação ocorra, são necessárias as informações sobre o mercado, processos, fornecedores, produtos concorrentes e da empresa, serviços, preços, fornecedores, clientes, entre outras. Essas 
informações possibilitam que os gestores e funcionários da empresa construam conhecimento e aprendam sobre o seu contexto por meio da criatividade (OTTONICAR, 2016). 0 uso da informação pode se concretizar pela inovação, já que é o resultado do acesso e avaliação da informação e nas MPE, isso não ocorre de maneira diferente.

As etapas de desenvolvimento de um projeto de inovação (risco, abrangência e intensidade, o conhecimento envolvido, as barreiras, impactos e aderência ao negócio e as externalidades) sugeridas pela FINEP (2016) podem ser guiados pelos padrões e indicadores de competência em informação que englobam as etapas do comportamento informacional. Nesse contexto, no processo de inovação o indivíduo busca as informações (comportamento informacional), avalia e usa as informações (competência em informação) para melhorar ou criar um produto/serviço novo.

Se contar com informações de qualidade, correta, de maneira clara e concisa e com a agilidade esperada, certamente o processo de inovação será eficaz e trará benefícios significativos para as MPE. Estas informações são estruturadas por meio do comportamento informacional e da competência em informação dos funcionários, isto significa que um não se desenvolve plenamente sem o outro, é necessário que essa inter-relação seja trabalhada em conjunto.

Sendo assim, a medida em que as MPE entendem a importância do comportamento informacional para o desenvolvimento de competências o resultado (a inter-relação explicitada na figura 2 será a geração de inovação e isso garantirá MPE altamente competitivas e com diferenciais significativos no mercado.

\section{CONSIDERAÇÕES FINAIS}

As organizações são complexas e existem incontáveis elementos em seu âmbito que merecem ser estudados para garantir avanços qualitativos. Entre estes diversos elementos entendemos que existem muitos aspectos que interferem no comportamento informacional dos indivíduos das organizações, por exemplo, as crenças, valores, cultura etc. dos indivíduos, que faz com que este busque a informação daquela maneira e não de outra. Portanto, estudar apenas o comportamento informacional sem também estudar as competências informacionais dos indivíduos é perder a oportunidade de gerar vantagem competitiva para as organizações.

A partir das discussões do trabalho foi possível refletir que apesar da competência em informação e o comportamento informacional serem pesquisados separadamente no contexto das MPE existe uma relação entre eles. As teorias se complementam por isso, perceber esta relação garante significativos benefícios para as organizações menores, Ciência da Informação e Administração de Empresas. Dessa maneira, o objetivo do trabalho de refletir sobre a relação do comportamento informacional e da competência em informação a fim de demonstrar como tais temáticas contribuem com o processo de inovação em micro e pequenas empresas foi atingido.

Desse modo, discutiu-se que para ser competente em informação é necessário que o indivíduo apresente o comportamento informacional. 0 funcionário da MPE precisa saber como buscar as informações, avaliar e usar e para isso se utiliza das habilidades e capacidades adquiridas no decorrer de sua experiência. A inovação necessita do uso da informação eficaz. 0 uso inteligente contribui com a geração de ideias e o desenvolvimento de produtos e serviços.

A pesquisa é importante para a sociedade, pois contribui para que o processo de inovação seja guiado pela competência em informação e o comportamento informacional. Tais diretrizes contribuem para que as micro e pequenas empresas cresçam e com isso: geram empregos, estimulam a educação e trazem renda para as comunidades locais.

Essa pesquisa se limita em relacionar alguns modelos específicos de comportamento informacional, competência em informação e inovação. Nesse sentido, outros modelos 
podem ser adotados em estudos futuros, bem como sua aplicação prática em micro e pequenas empresas.

\section{REFERÊNCIAS}

AMERICAN LIBRARY ASSOCIATION. Presidential Committee on Information Literacy. Chicago: ALA, 1989. Final report. Disponível em:< http://www.ala.org/acrl/publications/whitepapers/presidential >

ACRL. AMERICAN LIBRARY ASSOCIATION. First part of the draft framework for information literacy for higher education. Chicago: ALA, 2016. Disponível em: <http://acrl.ala.org/ilstandards/wpcontent/uploads/2014/02/Framework-for-IL-for-HE-Draft-1-Part-1.pdf $\geq$. Acesso em: 09 jan. 2017.

ANÍBAL, A. Da educação permanente à aprendizagem ao longo da vida e à validação das aprendizagens informais e não formais: recomendações e práticas. CIES e-Working Paper, n. 147, 2013. Lisboa: Centro de Investigação e Estudos de Sociologia; Instituto Universitário de Lisboa.

BELLUZZO, R. C. B. Construção de mapas: desenvolvendo competências em informação e comunicação. Bauru: Cá Entre Nós, 2007.

. Relatório final apresentado ao Programa de Pós-Doutorado em Gestão Escolar, da Faculdade de Filosofia, Ciências e Letras de Araraquara. Araraquara: UNESP, 2003.

. Construção de mapas: desenvolvendo competências em informação e comunicação. 2.ed. Bauru: Cá Entre Nós, 2007. v.1.

BELLUZZO, R. C. B.; FERES, G. G. Competência em informação, redes de conhecimento e as metas educativas para 2021: reflexões e inter-relações. In: BELLUZZO, R. C. B; FERES, G. G.; VALENTIM, M. L. P. (Orgs.). Redes de conhecimento e competência em informação: interfaces da gestão, mediação e uso da informação/organização. Rio de Janeiro: Interciência, 2015. p.1-35.

BRASIL. Lei n. 10.973 de 2004. Dispõe sobre incentivos à inovação e à pesquisa científica e tecnológica no ambiente produtivo. Disponível em: < http://www.planalto.gov.br/ccivil_03/_Ato20042006/2004/Lei/L10.973.htm> Acesso em: 02 nov. 2017.

BRASIL. Lei n. 123 de 2006. Dispõe sobre o Estatuto Nacional da Microempresa e da Empresa de Pequeno Porte. Disponível em:

<http://www.receita.fazenda.gov.br/Legislacao/LeisComplementares/2006/leicp123.htm> Acesso em: 02 nov. 2017.

BRASIL. Lei n. 11.196 de 2005. Dispõe sobre Incentivos fiscais para a inovação tecnológica. Disponível em: < http://www.planalto.gov.br/ccivil_03/_ato2004-2006/2005/lei/111196.htm > Acesso em: 02 nov. 2017.

BRASIL. Lei Complementar n. 155 de 2016. Altera a Lei Complementar no 123, de 14 de dezembro de 2006. Disponível em: < http://www.planalto.gov.br/ccivil_03/leis/lcp/Lcp155.htm\#art1 > Acesso em: 09 jan. 2018.

BRUCE, C. S. Workplace experiences of information literacy. International Journal of Information Management, v.19, p. 33-47, 1999.

CASE, D. O. Looking for information. 2.ed. Amsterdam: Elsevier; Academic Press, 2007.

CAMPELLO, B. O movimento da competência informacional: uma perspectiva para o letramento informacional. Ciência da Informação, Brasília, v.32, n.3, p.28-37, set./dez., 2003. 
COUTINHO, C.; LISBÔA, E. Sociedade da informação, do conhecimento e da aprendizagem: desafios para educação no século XXI. Revista de Educação, v. 18, n. 1, 2011.

FINEP. Programa de Investimento Direto em Empresas Inovadoras. Disponível em: $<$ http://www.finep.gov.br/apoio-e-financiamento-externa/programas-elinhas/descentralizacao/inovacred> Acesso em: 02 mar. 2016.

GASQUE, K. C. D. G; COSTA, S. M. S. Evolução teórico-metodológica dos estudos de comportamento informacional de usuários. Ciência da Informação, Brasília, v.39, n.1, p.21-32, jan./abr., 2010.

GONÇALVES, A.; KOPROWSKI S. O. Pequena empresa no Brasil. São Paulo: Edusp, 1995.

LIMA, T. C. S. de; MIOTO, R. C. T. Procedimentos metodológicos na construção do conhecimento científico: a pesquisa bibliográfica. Rev. Katálysis, Florianópolis, v.10 n.esp., p. 37-45, 2007.

LLOYD, A. Recasting information literacy as sociocultural practice: implications for library and information science researchers. Information Research, v. 12, n 4, 2007. Disponível em: <http://InformationR.net/ir/12-4/colis34.html>. Acesso em: 02 jan. 2018.

MATINEZ-SILVEIRA, M.; ODDONE, N. Necessidades e comportamento informacional: conceituação e modelos. Ciência da Informação, Brasília, v.36, n.1, p.118-127, maio/ago. 2007.

OECD. Organização para a Cooperação Econômica e Desenvolvimento. Manual de Oslo: proposta de diretrizes para coleta e interpretação de dados sobre inovação tecnológica. 3.ed., 2004. Disponível em:< http://www.finep.gov.br/images/apoio-e-financiamento/manualoslo.pdf>. Acesso em: 3 maio 2017.

G20 Innovation Report 2016. Disponível em: <https://www.oecd.org/sti/inno/G20innovation-report-2016.pdf >. Acesso em: 3 maio 2017.

OTTONICAR, S. L. C. Análise teórico-descritiva da competência em informação de gestores como fator de competitividade das indústrias de eletroeletrônicos da cidade de Garça/SP. 272f. 2016. Dissertação (Mestrado em Ciência da Informação) - Programa de Pós-Graduação em Ciência da Informação, Universidade Estadual Paulista, Marília, 2016.

OTTONICAR, S. L. C.; VALENTIM, M. L. P.; FERES, G. G. Competência em informação e os contextos educacional, tecnológico, político e organizacional. RICI: Revista Ibero-americana de Ciência da Informação, Brasília, v. 9, n. 1, p. 124-142, jan./jun. 2016.

PORTER, M. Vantagem competitiva: criando e sustentando um desempenho superior. 15. ed. Rio de Janeiro: Campus, 1989.

POZO, J. I. A Sociedade da Aprendizagem e o Desafio de Converter Informação em Conhecimento. Revista pátio, v. 8, ago./out. 2004. Disponível em: < http://www.udemo.org.br/A\%20sociedade.pdf> Acesso em: 17 ago 2017.

QUANDT, O. C. Inovação em clusters emergentes. Disponível em: < http://www.comciencia.br/reportagens/2004/08/13.shtml > Acesso em: 01 ago. 2017.

RANK, L.; EMEDIATO, G.; OSORIO, H. H. G. Manual de inovação. Brasília: Movimento Brasil Competitivo, 2008. Disponível em: <http://www.utfpr.edu.br/patobranco/estruturauniversitaria/diretorias/direc/nit/publicacoes/ManualdeInovao.pdf> Acesso em: 17 dez. 2017.

RASTELI, A.; CAVALCANTE, L. E. A competência em informação e o bibliotecário mediador da leitura em biblioteca pública. Encontros Bibli, v. 18, n. 36, p. 157-180, jan./abr., 2013. 
RODRIGUES, M. E. 0 conhecimento nas micro e pequenas empresas: um estudo sobre sua absorção e utilização nas micro e pequenas empresas fluminenses. 2000. Dissertação (Mestrado em Administração) - Universidade federal do Rio de Janeiro, Rio de Janeiro, 2000.

SCHELL, J. Guia para gerenciar pequenas empresas: como fazer a transição para uma gestão empreendedora. Rio de Janeiro: Campus, 1995.

SEBRAE/PR. Guia para a inovação: instrumento para a melhoria das dimensões da inovação. Curitiba: Sebrae/PR, 2015.

SEBRAE/SP. Panorama dos pequenos negócios. São Paulo: Sebrae/SP, 2017.

UNESCO. Global media and information literacy assessment framework: country readiness and competencies. Paris: UNESCO, 2013.

VASCONCELOS, F. C; CYRINO, Á. B. Vantagem competitiva: os modelos teóricos atuais e a convergência entre estratégia e teoria organizacional. Revista de Administração de Empresas, São Paulo, v. 40, n.4, p. 20-37, 2000.

WILSON, T. D. Human information behavior. Informing Science Research, Colorado, v.3, n.2, 2000.

. Models in information behavior reserch. Journal of Documentation, Londres, v.55, n.3, p.249270, jun. 1999. Disponível em: <http://informationr.net/tdw/publ/papers/1999JDoc.html> Acesso em: 12 dez. 2017.

WILSON, T. D.; WALSH, C. Information behavior: an interdisciplinary perspective. Sheffield: University of Sheffield, 1996. Disponível em: <http://informationr.net/tdw/publ/infbehav/cont.html>. Acesso em: ago. 2015.

WILSON, T. D. On user studies and information needs. Journal of Documentation, v. 31, n. 1, p. 3-15, 1981.

YAFUSHI, C. A. P. A Competência em informação para a construção de conhecimento no processo decisório: estudo de caso na Duratex de Agudos (SP). 232 f. Dissertação (Mestrado em Ciência da Informação) - Faculdade de Filosofia e Ciências, Universidade Estadual Paulista, Marília, 2015.

Editores do artigo: Enrique Muriel-Torrado e Adilson Luiz Pinto 